\title{
Low Temperature Growth of Carbon Nanomaterials on the Polymer Substrate Using Ion Assisted Microwave Plasma CVD
}

\author{
Raman Bekarevich ${ }^{1,2}$, Shota Miura ${ }^{1}$, Akihisa Ogino ${ }^{1}$, Aleksandr \\ V. Rogachev ${ }^{2}$, and Masaaki Nagatsu ${ }^{1}$ \\ ${ }^{I}$ Nanovision Department, Graduate School of Science and Technology, \\ Shizuoka University, 3-5-1 Joho-ku, Hamamatsu 432-8011, Japan \\ ${ }^{2}$ Department of Optics, Homel State University, \\ 104 Sovetskaya str., Homel 246-019, Belarus
}

\begin{abstract}
In this study, the successful growth of carbon nanotubes and few-layered graphene sheets on the silicon and polyimide substrates at relatively low temperature of $230 \sim 260^{\circ} \mathrm{C}$ by microwave surface wave plasma CVD technique has been demonstrated. Graphite-encapsulated $\mathrm{Ni}$ nanoparticles have been used as the catalyst for growing carbon nanomaterials (CNMs) in $\mathrm{NH}_{3} / \mathrm{CH}_{4}$ plasma. The results of high-resolution transmission electron microscope(TEM) analysis show the effect of substrate on the structure of CNMs.
\end{abstract}

Keyword: carbon nanotubes, few-layered graphene, high-resolution TEM, microwave plasma CVD

\section{Introduction}

Carbon nanotubes (CNTs) have been firstly obtained in 1991 by arc-discharge evaporation method [1]. Since that time, they are of interest to material scientists around the world. It has been found that CNTs possess excellent chemical, physical, mechanical and other properties [2-4] because the two-dimensional arrangement of carbon atoms in a graphene sheet allows large out-of-plane distortions, while the strength of carbon-carbon in-plane bonds keeps the graphene sheet exceptionally strong against any in-plane distortion or fracture [4]. Graphene, experimentally discovered in 2004 by mechanical exfoliation method [5], also is very attractive material with extraordinary properties [6].

CNTs and graphene have different potential applications [6-12]. However, to apply carbon nanomaterials (CNMs) in the real devices it is necessary to develop methods of large-size synthesis at low temperature where the structure and chemical composition of the substrates remain unaltered. It is possible to produce CNTs and graphene by several methods [1,5,13-17], but one of the most promising ways to realize low temperature growth of CNMs is the plasma-enhanced chemical vapor deposition (PECVD) [18-23], because the presence of highly reactive plasma environment decreases the activation energy of the CNT growth process [18]. One of the most popular sources of high density plasma applied in PECVD to grow CNTs is a microwave radiation [24-26].

Usually the PECVD methods require transition metals or their compounds as catalyst $[18,19,25,26]$. Yamazaki, et al. [19] have grown CNTs at temperature below $400^{\circ} \mathrm{C}$ by a remote PECVD with Co catalytic nanoparticles deposited by the impactor method on the $\mathrm{TiN} / \mathrm{SiO}_{2} / \mathrm{Si}$ substrates. At this experiment has been used the gas mixture of 


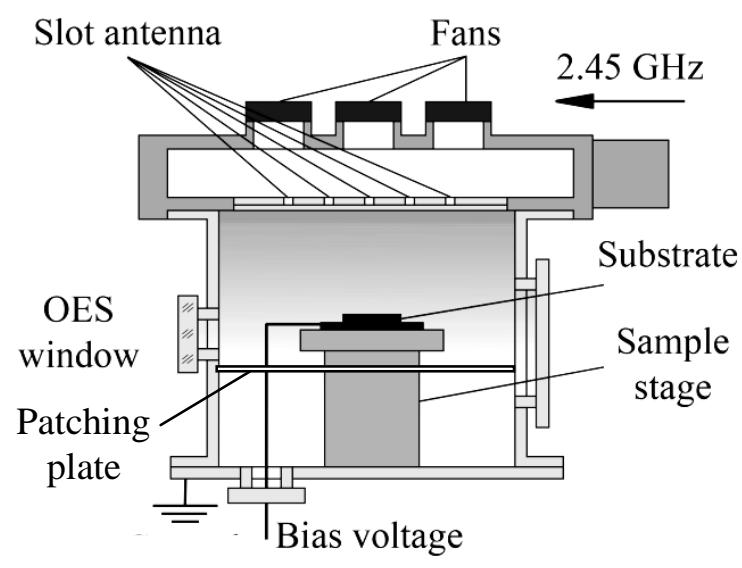

Figure 1. Schematic drawing of the experimental setup.

methane and hydrogen. In the reference [25], the Co catalyst prepared by sol-gel method has been used to grow CNMs, where the samples were heated up to $280 \sim 330^{\circ} \mathrm{C}$ by $\mathrm{Ar} / \mathrm{CH}_{4}$ or $\mathrm{Ar} / \mathrm{He} / \mathrm{CH}_{4}$ microwave plasma. Chang, et al. [26] converted Ni catalyst from the film into particles by microwave $\mathrm{H}_{2} / \mathrm{N}_{2}$ plasma and after that he used $\mathrm{CH}_{4} / \mathrm{H}_{2}$ plasma to realize the $\mathrm{CNTs}$ growth at the temperature of $250^{\circ} \mathrm{C}$.

As has been shown by Kim et al. [23] microwave plasma CVD (MPCVD) also can be available for graphene films synthesis in presence of $\mathrm{Al}$ sublayer at $400{ }^{\circ} \mathrm{C}$. Malesevic, et al. [27] used $\mathrm{CH}_{4} / \mathrm{H}_{2}$ microwave plasma with maximum input power of $2 \mathrm{~kW}$ to grow few-layered graphene. These former methods showed difficulties in synthesis of monolayer graphene, and graphene was synthesized at a relatively high temperature

In this study, the successful growth of CNTs and few-layered graphene sheets on silicon and polyimide substrates at relatively low temperature of $230 \sim 260^{\circ} \mathrm{C}$ by MPCVD technique has been demonstrated. Graphiteencapsulated $\mathrm{Ni}$ nanoparticles (GNNs) have been used as the catalyst for growing CNTs in $\mathrm{NH}_{3} / \mathrm{CH}_{4}$ plasma.

\section{Experimental}

In this work, GNNs with typical size of grain within $10-20 \mathrm{~nm}$ produced by DC arc-discharge method [28] has been used as catalyst. The polished (100) n-type silicon wafers and polyimide sheets covered with GNNs have been placed in the stainless steel vacuum chamber of the microwave

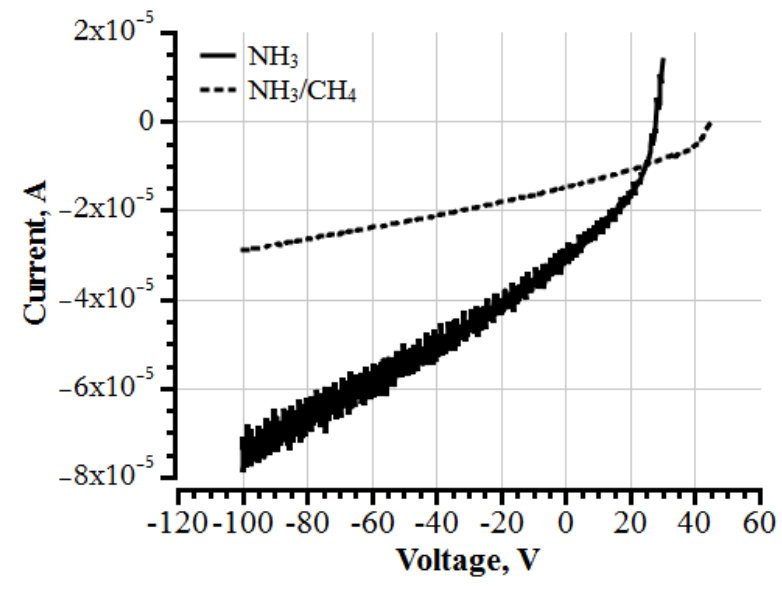

Figure 2. V-I characteristics of ammonia and ammonia/ methane microwave plasmas.

surface-wave plasma equipment (Figure 1) on the stage located at $110 \mathrm{~mm}$ below the top of chamber. The CNMs have been produced by introducing $2.45 \mathrm{GHz}$ microwaves through a quartz window via slot antennas [25].

The ammonia plasma has been introduced as the pre-treatment to make the catalyst active. Then the ammonia/methane mixture of gases has been used to synthesize the CNMs. At the step of pre-treatment square pulsed bias voltage from $-100 \mathrm{~V}$ to $+25 \mathrm{~V}$ (ion current densities are 15.4 and $0.8 \mathrm{~mA} / \mathrm{cm}^{2}$ respectively) with frequency of $500 \mathrm{~Hz}$ and duty ratio of $50 \%$ has been applied. During the CNMs growth we applied pulsed bias voltage from $-30 \mathrm{~V}$ to $+40 \mathrm{~V}$ (ion current densities are 32 and $0.07 \mathrm{~mA} / \mathrm{cm}^{2}$ respectively) with the same frequency, waveform and duty ratio. Here values of +25 and $+40 \mathrm{~V}$ are floating potentials founded by Langmuir probe measurements (Figure 2) for ammonia and ammonia/methane plasma respectively. Later when we talk about the values of the bias voltage will be called only a negative value of the first half period, as the floating potentials remain the same because we always apply it to balance the electron and ion currents. The working pressure of both the plasma pre-treatment and the growth process has been fixed at $20 \mathrm{~Pa}$. The maximum microwave power was $700 \mathrm{~W}$.

Although no heating stage has been applied, due to the heating effect of plasma itself, the substrates were heated up to $230 \sim 260{ }^{\circ} \mathrm{C}$ depending on the plasma discharge conditions. The temperature of the sample holder has been measured by a thermocouple during the plasma process. High-resolution transmission 

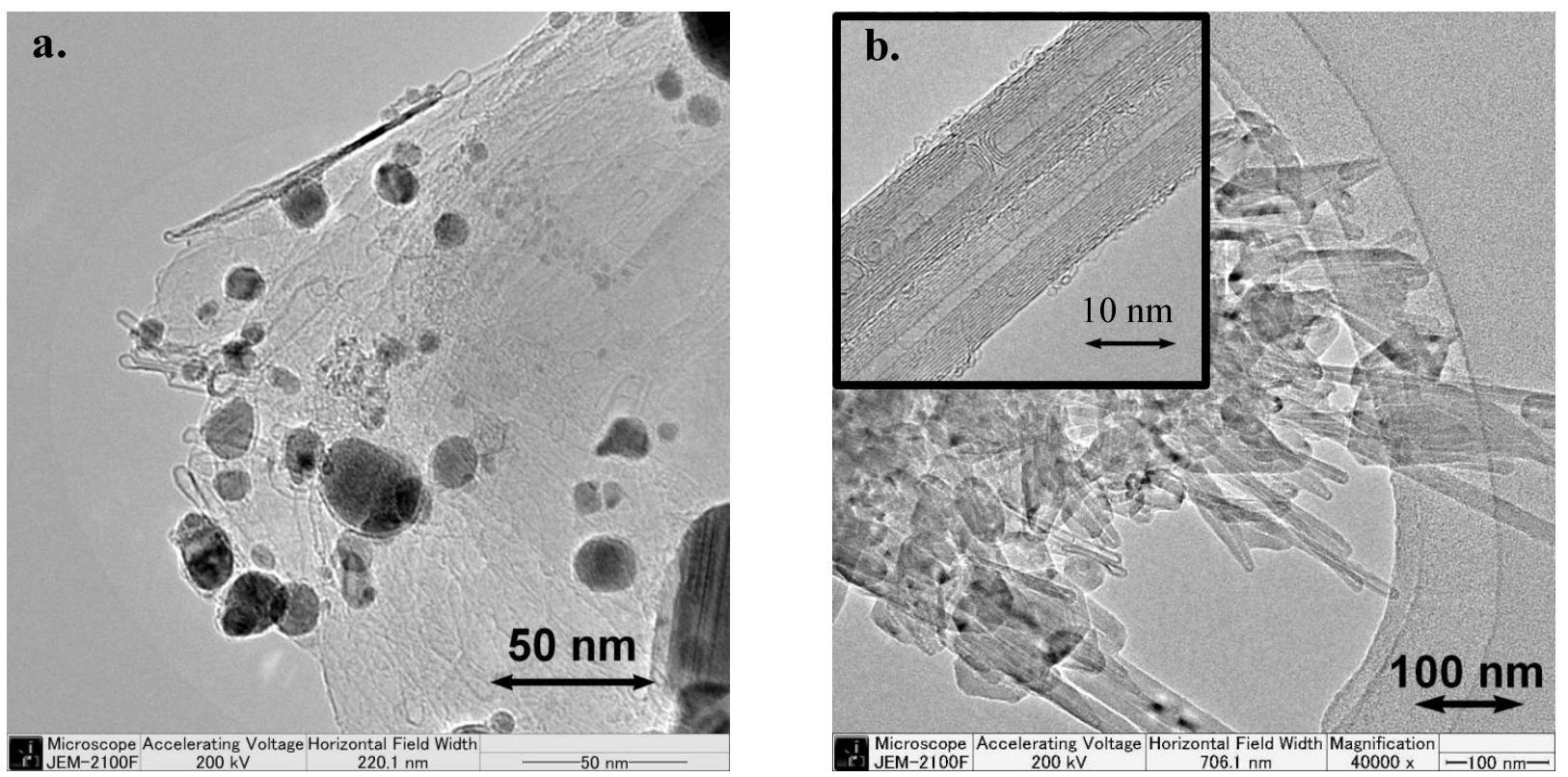

Figure 3. CNTs obtained onto Si substrate: a. $-\mathrm{NH}_{3} / \mathrm{CH}_{4}$ ratio is $100 / 20 \mathrm{sccm}$; b. $-\mathrm{NH}_{3} / \mathrm{CH}_{4} \mathrm{ratio}$ is $100 / 30 \mathrm{sccm}$.

electron microscopy instrument (HRTEM) JEOL JEM-2100F at an operating voltage of $200 \mathrm{kV}$ has been used to analyze morphology and detailed structure of the CNMs. Raman spectroscopy has been used to characterize CNMs grown on silicon and polyimide substrates using JASCO NR-1800 Raman spectrophotometer with $\mathrm{Ar}^{+}$ion laser at a wavelength of $514.5 \mathrm{~nm}$.

\section{Results and Discussion}

Two parameters of CNMs growth have been investigated during the treatment process: gas flow mixture ratio and bias voltage.

To define the optimal gas flow ratio we introduced different $\mathrm{NH}_{3} / \mathrm{CH}_{4}$ proportions (from 100/1 to $100 / 50 \mathrm{sccm}$ ) to the microwave plasma system. The other parameters have been fixed. The optimum $\mathrm{NH}_{3} / \mathrm{CH}_{4}$ proportion in the process of treatment has been obtained by analyzing the morphology of the grown CNTs by HRTEM. It can be seen From Figure $3 \mathrm{a}$ that multi-walled CNTs with the typical diameters ranged around $5 \mathrm{~nm}$ and the typical lengths $50-60 \mathrm{~nm}$ start growing when the $\mathrm{NH}_{3} / \mathrm{CH}_{4}$ gas flow proportion is $100 / 20 \mathrm{sccm}$. The CNTs grown from $\mathrm{NH}_{3} / \mathrm{CH}_{4}=100 / 30$ proportion possess longer tube length, higher tube density and straightness in comparison with those grown from the other gas flow mixture proportions. It is clearly seen there that in this case a lot of bamboo-liked multiwalled CNTs with typical lengths ranged from 200-300 $\mathrm{nm}$ to several micrometers and diameters within 15-25 $\mathrm{nm}$ are observed. This value is roughly corresponding to the typical sizes of the catalytic Ni grains. It is seen on the highest resolved HRTEM pictures that the walls of CNTs consist of many layers of carbon sheets with an average interlayer spacing of $0.34 \mathrm{~nm}$.

To confirm the biasing effect on the CNTs growth, we fixed $\mathrm{NH}_{3} / \mathrm{CH}_{4}$ ratio at $100 / 20 \mathrm{sccm}$ as the threshold value and applied pulse bias voltage within $-10 \sim-50 \mathrm{~V}$. The optimum bias voltage during the treatment has also been obtained by analyzing the morphology. It has been found that CNTs are growing with negatively voltage from $-20 \mathrm{~V}$ to $-30 \mathrm{~V}$. There is no observation of CNTs growth process in the case of higher bias voltage because of the strong etching effect.

Raman spectrum with Lorentzian shape analysis of CNTs obtained at the defined optimal conditions $\left(\mathrm{NH}_{3} / \mathrm{CH}_{4}\right.$ ratio is $100 / 30$, bias voltage is $-30 \mathrm{~V}$ ) is presented at the Figure 4. This spectrum shows strong D and G-bands, which correspond to the typical CNTs vibration modes. The bands are ascribed to the disorder-induced (D) mode at $1350 \mathrm{~cm}^{-1}$, the $\mathrm{C}-\mathrm{C}$ stretching tangential $(\mathrm{G})$ mode at $1582 \mathrm{~cm}^{-1}$, and the disorder-induced $\left(\mathrm{D}^{\prime}\right)$ mode at $1620 \mathrm{~cm}^{-1}$ [29]. D-band can be fitted 


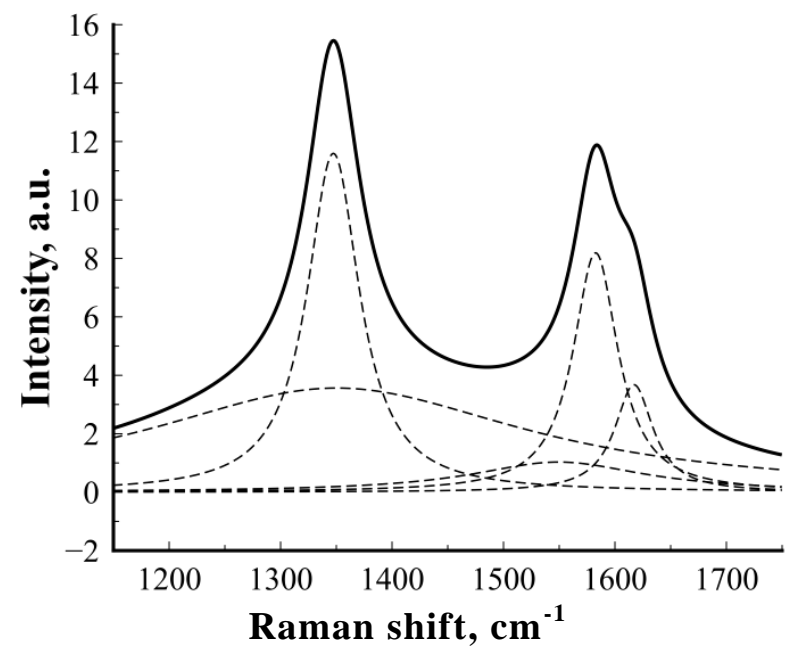

Figure 4. Typical Raman spectrum of CNTs obtained onto the $\mathrm{Si}$ substrate $\left(\mathrm{NH}_{3} / \mathrm{CH}_{4}\right.$ ratio is $100 / 30 \mathrm{sccm}$ )

by two Lorentzians, that can mean high graphite content in the sample[30]. The distinct shoulder of CNTs near $1620 \mathrm{~cm}^{-1}$ (D'-band) originates from the A1g tangential Raman mode for MWNTs [31]. The intensity of D-band peak is slightly stronger than that of G-band peak, which might be caused by defects of MWCNTs [32].

When optimal conditions for CNTs growth on the $\mathrm{Si}$ substrates have been defined we tried to realize low-temperature synthesis of CNMs on the polyimide substrate at the same conditions. Figure 5 illustrates HRTEM pictures of CNMs obtained onto the polyimide substrate. It is seen that CNTs with almost the same parameters, as in the case of $\mathrm{Si}$ substrates are formed. However, the main material formed onto the polyimide substrates is few-layered graphene sheets with characteristic size of several squared micrometers (Figure 5b). The highest resolved image easily reveals the crystalline structure of the material. The fast-Fourier transform also clearly shows crystalline structure of the sample. So far, to synthesize the graphene sheet using microwave plasma, $\mathrm{Cu}$ or $\mathrm{Ni}$ substrate was used as the catalyst. In the present work, we have successfully demonstrated the growth of graphene sheets onto the polyimide substrate at low temperature using microwave plasma CVD with GNN particles.

\section{Conclusion}

To evaluate possibility of the low-

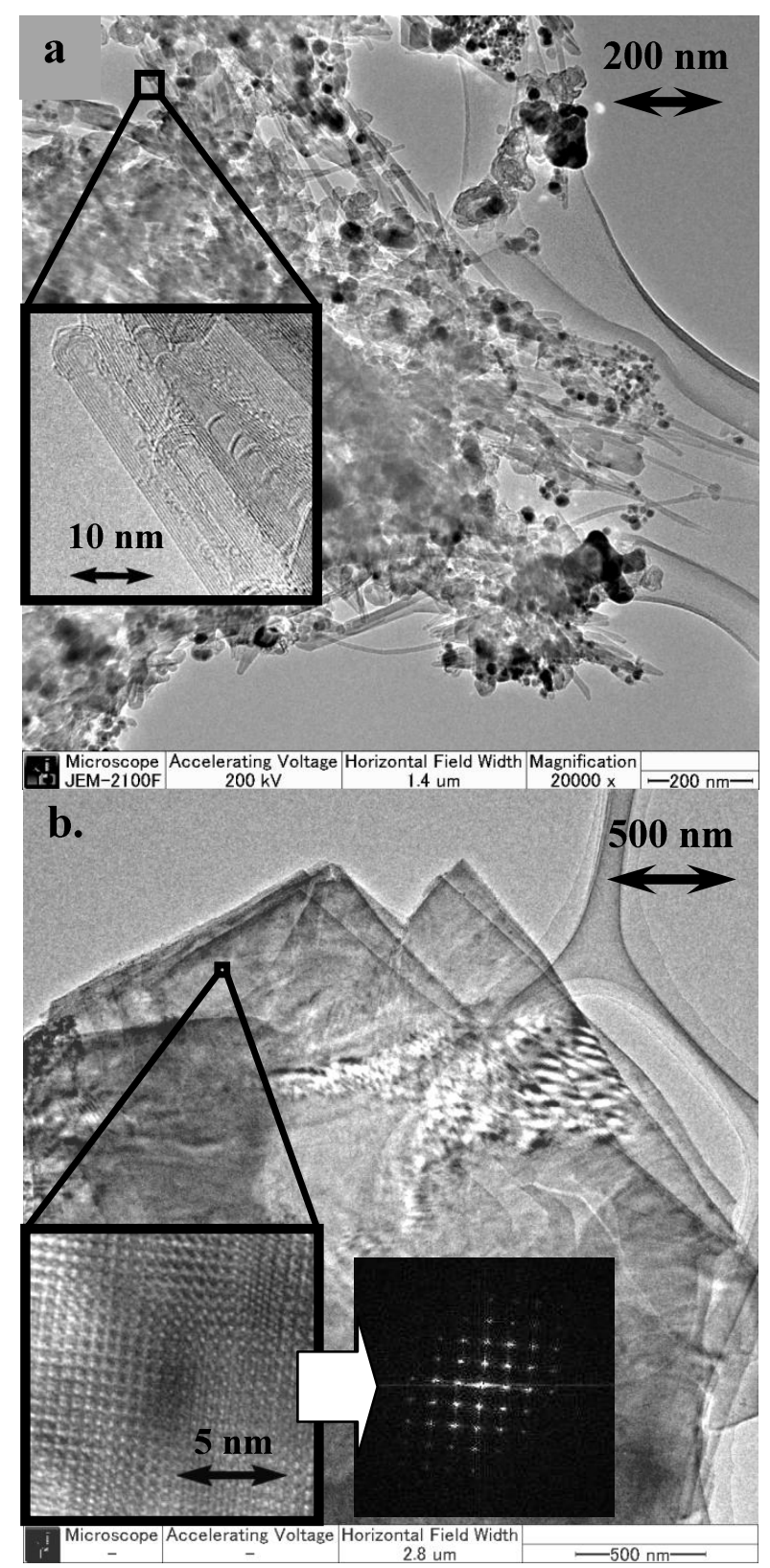

Figure 5. HRTEM pictures of CNMs obtained onto the polyimide substrates: a. CNTs; b. few-layered graphene sheets.

temperature $\left(230 \sim 260{ }^{\circ} \mathrm{C}\right) \mathrm{CNTs}$ growth, the optimal gas flow rate ratio has been investigated for $\mathrm{NH}_{3} / \mathrm{CH}_{4}$ surface wave plasma CVD. The CNTs grown under the gas mixture ratio at $\mathrm{NH}_{3} / \mathrm{CH}_{4}=100 / 30$ possess longer tube length, higher tube density and straightness in comparison with those grown from the other gas flow mixture proportions. Hereby, this work shows a possibility of growth of CNTs and few-layered graphene sheets from $\mathrm{NH}_{3} / \mathrm{CH}_{4}$ environment at a relatively low temperature directly on polymer substrate by existing microwave 
surface-wave plasma CVD method.

The results of HR-TEM investigations show the greatly influences of nature of the substrate on the structure of grown CNMs. The origin of the obtained CNTs and few-layered graphene sheets needs to be further investigated in future experiments.

\section{Acknowledgements}

This work was supported in part by a Grant-in-Aid for Scientific Research (Grant No. 2110010) from the Japan Society for the Promotion of Science (JSPS).

\section{References}

1. S. Iijima, Nature 354 (1991) 56-58.

2. P. Ayala, R. Arenal, A. Loiseau, A. Rubio, T Pichler, Rev. Mod. Phys. 82 (2010) 1843-85.

3. P. R. Bandaru, J. Nanosci. Nanotechno. 7 (2007) 1239-67.

4. J. A. Kim, D. G. Seong, T. J. Kang, J. R. Youn, Carbon 44 (2006) 1898-905.

5. K. S. Novoselov, A. K. Geim, S. V. Morozov, D. Jiang, Science 36 (2004) 666-9.

6. Y. Zhu, S. Murali, W. Cai, X. Li, J. W. Suk, J. R. Potts, R. S. Ruoff, Adv. Mat. 22 (2010) 3906-24.

7. A. K. Feldman, M. L. Steigerwald, X. Guo, C. Nuckolls, Acc. Chem. Res. 41 (2008) 1731-41.

8. L. Agui, P. Yanez-Sedeno, J. M. Pingarron, Anal. Chim. Acta 622 (2008) 11-47.

9. H. J. Jeong, H. D. Jeong, H. Y. Kim, J. S. Kim, S. Y. Jeong, J. T. Han, D. S. Bang, G. W. Lee, Adv. Func. Mat. 21 (2011) 1526-32.

10. T. Chen, S. Wang, Z. Yang, Q. Feng, X. Sun, L. Li, Z. S. Wang, H. Peng, Angew. Chem. Int. Edit. 50 (2011) 1815-9.

11. P. Blake, P. D. Brimicombe, R. R. Nair, T. J. Booth, D. Jiang, F. Schedin, L. A. Ponomarenko, S. V. Morozov, H. F. Gleeson, E. W. Hill, A. K. Geim, K. S. Novoselov, Nano Lett. 8 (2008) 1704-8.

12. Z. Sun, T. Hasan, F. Torrisi, D. Popa, G. Privitera, F. Wang, F. Bonaccorso, D. M. Basko, A. C. Ferrari, Nano 4 (2010) 803-10.

13.H.W. Zhu, C.L. Xu, D.H. Wu, B.Q. Wei, R. Vajtai, P.M. Ajayan, Science 296 (2002) 884-6.

14.E. Joselevich, H. Dai, J. Liu, K. Hata, A.H.
Windle, Top. Appl. Phys. 111 (2008) 101-64.

15. C.-M. Seah, S.-P. Chai, A.R. Mohamed, Carbon 49 (2011) 4613-35.

16. N. Li, Z. Wang, K. Zhao, Z. Shi, Z. Gu, S. $\mathrm{Xu}$, Carbon 48 (2010) 255-9.

17. S. Garaj, W. Hubbard, J.A. Golovchenko, Appl. Phys. Lett. 97 (2010) 183103.

18. S. Hofmann, C. Ducati, J. Robertson, B. Kleinsorge, Appl. Phys. Lett. 83 (2003) 135.

19. Y. Yamazaki, N. Sakuma, M. Katagiri, M. Suzuki, T. Sakai, S. Sato, M. Nihei, Y. Awano, Appl. Phys. Exp. 1 (2008) 034004.

20. S.H. Lim, Z. Luo, Z. Shen, J. Lin, Nanoscale Res. Lett. 5 (2010) 1377-86.

21.A. Dato, V. Radmilovic, Z. Lee, J. Phillips, M. Frenklach, Nano Lett. 8 (2008) 2012-6.

22. G. Nandamuri, S. Roumimov, R. Solanki, Appl. Phys. Lett. 96 (2010) 154101.

23. Y. Kim, W. Song, S.Y. Lee, C. Jeon, W. Jung, M. Kim, C.-Y. Park, Appl. Phys. Lett. 98 (2011) 263106.

24. M.B. Assouar, M. Dossot, S. Rizk, C. Tiusan, J. Bougdira, Nanotechnology 21 (2010) 065708.

25. D. Lu, A. Ogino, T. Matsuda, Q. Ma, M. Nagatsu, J. Plasma Fus. Res. S. 8 (2009) 544-7.

26. S. C. Chang, T. C. Lin, T. S. Li, S. H. Huang, Microelectron. J. 39 (2008) 1572-5.

27. A. Malesevic, R. Vitchev, K. Schouteden, A. Volodin, L. Zhang, G. V. Tendeloo, A. Vanhulsel, C. V. Haesendonck, Nanotechnology 19 (2008) 305604.

28. M. Nagatsu, T. Yoshida, M. Mesko, A. Ogino, T. Matsuda, T. Tanaka, H. Tatsuoka, K. Murakami, Carbon 44 (2006) 3336-41.

29.P. B. Amama, C. Lan, B. A. Cola, X. Xu, R. G . Reifenberger, T. S. Fisher, J. Phys. Chem. C 112 (2008) 19727-33.

30. M. S. Dresselhaus, G. Dresselhaus, R. Saito, A. Jorio, Phys. Rep. 409 (2005) 47-99.

31. A. M. Rao, A. Jorio, M. A. Pimenta, M. S. S. Dantas, R. Saito, G. Dresselhaus, M. S. Dresselhaus, Phys. Rev. Lett. 84 (2000) 1820-3.

32. Q.W. Li, Y. Li, X. F. Zhang, S. B. Chikkannanavar, Y. H. Zhao, A. M. Dangelewicz, L. X. Zheng, S. K. Doorn, Q. X. Jia, D. E. Peterson, P. N. Arendt, Y. T. Zhu, Adv. Mat. 19 (2007) 3358-63. 